\title{
A Venezuela em teste: a qualidade da democracia venezuelana em ano eleitoral ${ }^{1}$
}

\author{
JoÃo CARLOS AMOROSO BOTELHO \\ Doutor em Ciência Política (Universidad de Salamanca, Espanha) \\ Professor da Universidade Federal de Goiás \\ Goiânia, Brasil \\ joaocarlosbotelho@hotmail.com
}

\begin{abstract}
Resumo As eleições presidenciais de 2013, que foram as mais acirradas desde a ascensão de Hugo Chávez, ofereceram uma oportunidade especial para a análise da qualidade da democracia na Venezuela. O artigo se diferencia ao fazer uma avaliação prévia sobre a continuidade ou não do regime democrático no país para, conforme o resultado, passar à análise da sua qualidade. Afinal, não se pode analisar a qualidade de algo que não exista. A partir da definição de critérios, com base em Dahl e O’Donnell, e variáveis, categorias e pontuações para cada critério, foi possível avaliar que, apesar dos problemas relativos a liberdade de imprensa, concentração de poderes no Executivo e falta de autonomia dos demais ramos de poder, a Venezuela continuava tendo uma democracia. Esse resultado considera a pontuação para o conjunto das variáveis, evitando que um problema, sozinho, implique a inexistência de democracia, a menos que esse problema signifique que não haja eleições competitivas e limpas. $\mathrm{Na}$ análise da qualidade democrática, a partir de metodologia definida por Morlino e colaboradores, a conclusão foi que há uma prioridade para a igualdade em detrimento da liberdade na dimensão de conteúdo, além de vários problemas na dimensão de procedimento.
\end{abstract}

Palavras-chave: Venezuela; qualidade da democracia; Hugo Chávez; ano eleitoral; Nicolás Maduro.

\section{Introdução}

$\mathrm{D}$ epois de Hugo Chávez conquistar em outubro de 2012 seu terceiro mandato presidencial seguido desde a Constituição de 1999, o ano de 2013 começou com uma reviravolta para a Venezuela. O eleito, que ainda não havia tomado posse, apesar de o período do seu novo mandato já ter se iniciado em 10 de janeiro com o então vice-presidente, Nicolás Maduro, não resistiu a um câncer na região pélvica e faleceu em 5 de março, criando a necessidade de convocação de novas eleições para 14 de abril.

Os dois principais concorrentes foram Maduro, que havia sido indicado por Chávez para disputar sua sucessão e assumido a Presidência depois da morte do padrinho político, função que já exercia na prática desde o início do novo mandato, e o candidato único das principais forças de oposição, o governador de Miranda, Henrique Capriles Radonski (Primeiro Justiça), que já havia sido derrotado por Chávez em outubro de 2012.

$1 \mathrm{O}$ artigo é parte de um projeto financiado pela FAPEG (Fundação de Amparo à Pesquisa do Estado de Goiás). 
Apesar de ter ocorrido mais uma vitória do chavismo, foi uma disputada muito apertada, em que Maduro venceu com $50,61 \%$ dos votos contra 49,12\% de Capriles. Foi a menor vantagem do grupo político de Chávez desde sua primeira eleição para presidente, em 1998. Além do desgaste natural com um período de 14 anos do mesmo governante no poder, a Venezuela foi afetada pela crise econômica mundial de 2008, por causa da sua dependência das exportações de petróleo. Outra questão que gera rejeição ao chavismo são os índices alarmantes de criminalidade. Ao mesmo tempo, pela terceira vez consecutiva, as principais forças de oposição concorreram com um candidato único. Bem avaliado como governador, Capriles já havia conquistado uma votação expressiva em 2012, de 44,31\%, e conseguiu elevar esse percentual no ano seguinte. Para reforçar seu potencial eleitoral, a ligação de Capriles com o grupo que articulou e promoveu o golpe de 2002 contra Chávez foi contrabalançada por programas de governo e um discurso político direcionados à área social, que tem sido a marca do chavismo.

Os momentos finais da apuração e os dias imediatamente posteriores à divulgação dos resultados foram conturbados. A derrota por uma margem estreita foi contestada por Capriles, que, alegando irregularidades no processo, como a coerção de eleitores, se negou a reconhecer os resultados até que uma recontagem dos votos fosse concluída. Para pressionar o CNE (Conselho Nacional Eleitoral) a acatar sua solicitação, o candidato de oposição convocou manifestações dos seus apoiadores, que resultaram em oito mortes.

Os protestos violentos levaram o próprio Capriles a retirar a convocação de manifestações. Ao mesmo tempo, as cerimônias de proclamação do vencedor pelo CNE e posse de Maduro na Assembleia Nacional foram realizadas nas datas previstas, assim como as felicitações ao eleito e os reconhecimentos dos resultados foram sendo emitidos por uma série de países, aos quais não se juntaram os Estados Unidos, que preferiram defender a recontagem dos votos e esperar.

O CNE, que já realiza uma auditoria de $54 \%$ das urnas eletrônicas, se negou inicialmente a atender a solicitação de Capriles, mas anunciou um dia antes da posse de Maduro que completaria a auditoria de 100\% das urnas, ressaltando, porém, que não se trataria de uma recontagem manual de todos os votos, conforme solicitado pelas principais forças de oposição. A auditoria da totalidade das urnas foi concluída em junho, sem o acompanhamento da oposição, que não aceitou os procedimentos, e confirmou os resultados.

Esse contexto político-eleitoral torna o ano de 2013 uma oportunidade especial para a observação do cenário venezuelano e a avaliação da qualidade da democracia do país. Com a vitória apertada de Maduro e a disputa que se seguiu a ela, o regime venezuelano esteve sob um teste importante, tanto durante a campanha eleitoral como nos momentos de realização das eleições, apuração dos votos e divulgação e conferência dos resultados.

Para a análise da qualidade da democracia venezuelana, um caso em que há controvérsia sobre se o regime continua sendo democrático (Corrales, 2006; Corrales e Penfold, 2007; e Kornblith, 2007), é necessário verificar em primeiro lugar se estão presentes os aspectos básicos que compõem uma definição minimalista de democracia, como a realização de eleições competitivas, livres, honestas e com sufrágio universal e a garantia das liberdades individuais. Caso se conclua que o regime é democrático, a tarefa seguinte será avaliar o quanto avançaram aspectos específicos para a qualidade de uma democracia que vão além das condições mínimas para sua existência, como os mecanismos de controle horizontal e vertical dos eleitos e servidores públicos em geral, a transparência da gestão, a preocupação dos políticos com o caráter público da sua função e a identificação da população com as regras do jogo democrático.

A análise tem como referência o ano de 2013, abrange até o primeiro semestre de 2015 e utiliza critérios e indicadores objetivos, o que possibilita que se conforme um panorama completo e aprofundado sobre a democracia na Venezuela depois dos 14 anos de Chávez no poder, evita uma abordagem de caráter ideológico, aproveita um momento oportuno para a coleta de dados e ajuda a elevar o nível de conhecimento público sobre o caso.

\section{Justificativa teórica e metodológica}

Dahl (2005) estabelece oito características que definem uma democracia e oferecem para a população de um país a possibilidade de formular preferências, expressá-las e vê-las consideradas na atuação dos seus governos. São elas: 1) liberdade de formar e participar de organizações; 2) liberdade de expressão; 3) direito de voto; 4) elegibilidade para cargos públicos; 5) direito de que líderes políticos disputem apoio; 6) fontes alternativas de informação; 7) eleições livres e idôneas; 8) e instituições para fazer com que as políticas governamentais dependam de eleições e outras expressões de preferência.

O'Donnell (2004) considera que esses atributos são insuficientes e inclui outros, como a conclusão do mandato pelos governantes e a inexistência de restrições aos poderes legais das autoridades eleitas por parte de atores não eleitos. Com seu esforço de revisão, ele identificou e explicou a possibilidade de variações na institucionalização dos regimes democráticos e criou as bases para uma agenda de pesquisa sobre a qualidade da democracia.

No caso da possibilidade de variações, não se trata de assinalar a existência de modelos distintos de democracia, 
como Lijphart (2003), e sim de chamar a atenção para o fato de que os regimes não se institucionalizam da mesma maneira. Portanto, não é cabível definir parâmetros com base nas democracias mais antigas dos países ocidentais desenvolvidos, como se fez na literatura sobre consolidação democrática, da qual a obra de Gunther, Diamandouros e Puhle (1995) é um exemplo, e esperar que a trajetória e os resultados em outras partes do mundo sejam os mesmos, o que justificaria o rótulo de democracia consolidada.

Com esses parâmetros, alguns casos estariam há décadas em processo de consolidação, o que é um contrassenso. O'Donnell mostrou, então, que há países em que a institucionalização do regime democrático se dá sem, ao mesmo tempo, o abandono de práticas consideradas nocivas e eliminadas ou controladas nas democracias mais antigas, como o clientelismo, classificando esses regimes de democracias informalmente institucionalizadas.

É, ao descrever esses regimes e tratar das condições de sua efetividade e seu funcionamento adequado, que O'Donnell cria as bases para a agenda de pesquisa sobre a qualidade da democracia, ainda que, inicialmente, ele não empregasse essa expressão. Suas preocupações nesse sentido aparecem desde o conceito de accountability horizontal, que se refere à presença e ao grau de controle das instituições do Estado por elas próprias, e chegam a questões de direitos civis, como a aplicação igualitária das leis, a igualdade de tratamento pelos órgãos públicos e a proteção aos direitos humanos.

Morlino, Dressel e Pelizzo (2011) apresentam os fundamentos teóricos para identificar e analisar as democracias informalmente institucionalizadas. A questão, que era se os países são mais ou menos democráticos, passa a ser o quão diferentemente os regimes informais são democráticos. Os autores enfatizam a necessidade de avaliar não mais a qualidade, já que não se pode assumir de antemão que todos os aspectos envolvidos caminham juntos, e sim as qualidades da democracia, e as dividem em três dimensões teoricamente distintas, que são as de procedimento, conteúdo e resultado.

A avaliação do regime democrático da Venezuela realizada pelo autor deste artigo em um trabalho de 2008 se baseia nos parâmetros de Dahl (2005) e O'Donnell (2000). Nos apêndices de "Poliarquia: participação e oposição", Dahl apresenta variáveis para sete dos oito requisitos que estabelece, abandonando o item elegibilidade para cargos públicos, e categorias para cada variável (ver quadros abaixo). Essas categorias, por sua vez, se baseiam em conceitos, não em indicadores, e recebem pontuações. Quanto menor a pontuação, melhor a situação em cada variável. Já nos trabalhos de O’Donnell enfocados aqui, não há esse tipo de abordagem.

\section{Condições para uma democracia e suas variáveis}

\begin{tabular}{|c|c|}
\hline Condição & Variáveis \\
\hline \multirow{2}{*}{ 1. Liberdade de formar e participar de organizações } & Liberdade de oposição de grupo \\
\hline & Articulação de interesses por grupos associativos \\
\hline 2. Liberdade de expressão & Liberdade de imprensa \\
\hline 3. Direito de voto & Sistema eleitoral vigente \\
\hline \multirow{4}{*}{ 4. Direito de que líderes políticos disputem apoio } & Articulação de interesses por partidos políticos \\
\hline & Sistema partidário: quantitativo \\
\hline & Liberdade de oposição de grupo \\
\hline & Sistema eleitoral vigente \\
\hline \multirow{3}{*}{ 5. Fontes alternativas de informação } & Liberdade de oposição de grupo \\
\hline & Liberdade de imprensa \\
\hline & Sistema partidário: quantitativo \\
\hline \multirow{4}{*}{ 6. Eleições livres e limpas } & Liberdade de oposição de grupo \\
\hline & Liberdade de imprensa \\
\hline & Sistema eleitoral vigente \\
\hline & Sistema partidário: quantitativo \\
\hline \multirow{4}{*}{$\begin{array}{l}\text { 7. Instituições para fazer com que as políticas governamen- } \\
\text { tais dependam de votos e outras expressões de preferência }\end{array}$} & Condição constitucional do atual regime \\
\hline & Agregação de interesses pelo Legislativo \\
\hline & Distribuição horizontal do poder \\
\hline & Condição atual do Legislativo \\
\hline
\end{tabular}

Fonte: Elaboração própria a partir de Dahl (2005, p. 217) 


\section{Categorias das variáveis e suas descrições e pontuações}

\begin{tabular}{|c|c|c|c|}
\hline Variável & Categorias & Conceitos & Pontos \\
\hline \multirow{4}{*}{$\begin{array}{l}\text { Liberdade de } \\
\text { imprensa }\end{array}$} & Completa & $\begin{array}{l}\text { Nenhuma censura ou controle governamental tanto da im- } \\
\text { prensa doméstica quanto de correspondentes estrangeiros }\end{array}$ & 1 \\
\hline & Intermitente & $\begin{array}{l}\text { Censura ocasional ou seletiva tanto da imprensa doméstica } \\
\text { quanto de correspondentes estrangeiros }\end{array}$ & 2 \\
\hline & Internamente ausente & $\begin{array}{l}\text { Censura estritamente doméstica e Nenhuma restrição à coleta } \\
\text { de informações por agências estrangeiras ou censura eletiva } \\
\text { das suas transmissões }\end{array}$ & 3 \\
\hline & $\begin{array}{l}\text { Interna e externamente } \\
\text { ausente }\end{array}$ & $\begin{array}{l}\text { Censura ou controle estritamente direto ou indireto, doméstico } \\
\text { ou estrangeiro }\end{array}$ & 4 \\
\hline \multirow{3}{*}{$\begin{array}{l}\text { Condição } \\
\text { constitucional do } \\
\text { atual regime }\end{array}$} & Constitucional & $\begin{array}{l}\text { Governo conduzido com referência a normas constitucionais } \\
\text { reconhecidas }\end{array}$ & 1 \\
\hline & Autoritário & $\begin{array}{l}\text { Nenhuma limitação constitucional efetiva ou recurso absoluta- } \\
\text { mente regular a poderes extraconstitucionais e exercício arbi- } \\
\text { trário do poder confinado largamente ao setor político }\end{array}$ & 2 \\
\hline & Totalitário & $\begin{array}{l}\text { Nenhuma limitação constitucional efetiva e amplo exercício do } \\
\text { poder pelo regime tanto na esfera política quanto na social }\end{array}$ & 3 \\
\hline \multirow{4}{*}{$\begin{array}{l}\text { Sistema eleitoral } \\
\text { vigente }\end{array}$} & Competitivo & $\begin{array}{l}\text { Nenhuma proibição partidária ou proibição apenas de partidos } \\
\text { extremistas ou extraconstitucionais }\end{array}$ & 1 \\
\hline & $\begin{array}{l}\text { Parcialmente } \\
\text { competitivo }\end{array}$ & Um partido com $85 \%$ ou mais dos assentos parlamentares & 2 \\
\hline & Não competitivo & Votação com lista ou nenhuma oposição eleita & 3 \\
\hline & Nenhuma eleição & $\begin{array}{l}\text { Eleições não realizadas regularmente ou suspensas pelo regime } \\
\text { no poder }\end{array}$ & 4 \\
\hline \multirow{4}{*}{$\begin{array}{l}\text { Liberdade de } \\
\text { oposição de grupo }\end{array}$} & Completa & $\begin{array}{l}\text { Grupos autônomos livres para entrar na política e capazes de } \\
\text { exercer oposição ao governo, exceto para grupos extremistas, } \\
\text { onde forem proibidos }\end{array}$ & 1 \\
\hline & Limitada & $\begin{array}{l}\text { Grupos autônomos livres para se organizar na política mas li- } \\
\text { mitados em sua capacidade de exercer oposição ao governo, o } \\
\text { que inclui a absorção de liderança de oposição real ou poten- } \\
\text { cial no governo }\end{array}$ & 2 \\
\hline & Informal & Grupos autônomos tolerados informalmente e fora da política & 3 \\
\hline & Ausente & Nenhum grupo genuinamente autônomo tolerado & 4 \\
\hline \multirow{4}{*}{$\begin{array}{l}\text { Articulação de } \\
\text { interesses por grupos } \\
\text { associativos }\end{array}$} & Significativa & - & 1 \\
\hline & Moderada & - & 2 \\
\hline & Limitada & - & 3 \\
\hline & Desprezível & - & 4 \\
\hline \multirow{4}{*}{$\begin{array}{l}\text { Articulação de } \\
\text { interesses por } \\
\text { partidos políticos }\end{array}$} & Significativa & - & 1 \\
\hline & Moderada & - & 2 \\
\hline & Limitada & - & 3 \\
\hline & Desprezível & - & 4 \\
\hline \multirow{4}{*}{$\begin{array}{l}\text { Agregação de } \\
\text { interesses pelo } \\
\text { Legislativo }\end{array}$} & Significativa & - & 1 \\
\hline & Moderada & - & 2 \\
\hline & Limitada & - & 3 \\
\hline & Desprezível & - & 4 \\
\hline
\end{tabular}




\begin{tabular}{|c|c|c|c|}
\hline Variável & Categorias & Conceitos & Pontos \\
\hline \multirow{6}{*}{$\begin{array}{l}\text { Sistema partidário: } \\
\text { quantitativo }\end{array}$} & Pluripartidário & $\begin{array}{l}\text { Governo de coalizão ou de partido minoritário normalmente } \\
\text { obrigatório se o sistema é parlamentarista }\end{array}$ & 1 \\
\hline & $\begin{array}{l}\text { Bipartidário ou } \\
\text { efetivamente } \\
\text { bipartidário }\end{array}$ & Expectativa razoável de rotatividade partidária & 2 \\
\hline & Um partido e meio & Oposição significativa, mas incapaz de conquistar a maioria & 3 \\
\hline & Um partido dominante & $\begin{array}{l}\text { Oposição, mas numericamente ineficaz em nível nacional. In- } \\
\text { clui a participação minoritária no governo enquanto mantém a } \\
\text { identidade partidária para fins eleitorais }\end{array}$ & 4 \\
\hline & Partido único & $\begin{array}{l}\text { Todos os outros inexistem, foram proibidos, não participam ou } \\
\text { são adjuntos do partido dominante na atividade eleitoral. Inclui } \\
\text { "frentes nacionais" e sistemas eleitorais unipartidários }\end{array}$ & 5 \\
\hline & Não sistema & Nenhum partido ou todos os partidos ilegais ou ineficazes & 6 \\
\hline \multirow{3}{*}{$\begin{array}{l}\text { Distribuição } \\
\text { horizontal do poder }\end{array}$} & Significativa & $\begin{array}{l}\text { Alocação efetiva de poder a órgãos legislativos, executivos e } \\
\text { judiciários funcionalmente autônomos }\end{array}$ & 1 \\
\hline & Limitada & $\begin{array}{l}\text { Um braço do governo sem genuína autonomia funcional, ou } \\
\text { dois braços com limitada autonomia funcional }\end{array}$ & 2 \\
\hline & Desprezível & $\begin{array}{l}\text { Predominância completa do governo por um braço ou por uma } \\
\text { agência extragovernamental }\end{array}$ & 3 \\
\hline \multirow{4}{*}{$\begin{array}{l}\text { Condição atual do } \\
\text { Legislativo }\end{array}$} & Plenamente efetivo & $\begin{array}{l}\text { Realiza a função legislativa normal como braço razoavelmente } \\
\text { "co-igual" do governo nacional }\end{array}$ & 1 \\
\hline & Parcialmente efetivo & $\begin{array}{l}\text { Tendência para a dominação pelo Executivo ou então parcial- } \\
\text { mente limitado no exercício efetivo da função legislativa }\end{array}$ & 2 \\
\hline & Largamente ineficaz & $\begin{array}{l}\text { Dominação virtualmente total pelo Executivo ou por uma orga- } \\
\text { nização de partido único ou partido dominante }\end{array}$ & 3 \\
\hline & Totalmente ineficaz & $\begin{array}{l}\text { Restrito à função legislativa consultiva ou endossante ou sem } \\
\text { Legislativo }\end{array}$ & 4 \\
\hline
\end{tabular}

Fonte: Elaboração própria a partir de Dahl (2005, p. 218-221)

A partir das variáveis usadas por Dahl (2005) e dos aspectos enfatizados por O’Donnell (2000), o autor deste artigo realizou as classificações ou definiu indicadores no seu trabalho de 2008, buscando e apresentando dados empíricos para cada item. Com isso, pôde avaliar a democracia venezuelana e identificar os problemas naquele momento, que se concentravam na separação e na independência dos Poderes.

Agora, em um momento diferente e importante, essa metodologia será aproveitada, reforçando sua fundamentação empírica e aprimorando a avaliação da qualidade da democracia, para levar em conta, além de questões enfatizadas por O'Donnell (2000), como a igualdade de tratamento pelos órgãos públicos e a proteção aos direitos humanos, aspectos relativos às três dimensões estabelecidas por Morlino, Dressel e Pelizzo (2011).
Para esses três autores, como a democracia é multidimensional, não se pode assumir de antemão que todos os elementos da sua qualidade caminham juntos, criando um sistema para classificar o quão bem os regimes se saem nesse quesito. A atenção precisa se direcionar para como a democracia opera procedimentalmente, quanta liberdade e igualdade ela promove e quanta responsividade e legitimidade ela consegue oferecer com seu desempenho nas questões anteriores, relacionadas a procedimento e conteúdo.

Adotando os postulados de que os países não podem ser classificados com base em uma única virtude democrática e de que todos os componentes de uma democracia de qualidade não caminham necessariamente juntos, se admite em termos teóricos a possibilidade de que um regime se saia bem em determinados aspectos e não tão bem em outros. 
Para cada uma das três dimensões da qualidade de uma democracia, que se referem a procedimento, conteúdo e resultado, Morlino, Dressel e Pelizzo estabelecem ao menos uma subdimensão e os respectivos indicadores para medi-las (ver quadro abaixo).

\section{Dimensões da qualidade democrática e suas subdimensões e indicadores}

\begin{tabular}{|c|c|c|}
\hline Dimensão & Subdimensões & Indicadores \\
\hline \multirow{10}{*}{ Procedimento } & \multirow{3}{*}{ Estado de Direito } & Respeito do governo à integridade dos cidadãos \\
\hline & & Eficácia do governo \\
\hline & & Grau de corrupção \\
\hline & \multirow{2}{*}{ Accountability eleitoral } & Liberdade de imprensa \\
\hline & & Autodeterminação eleitoral \\
\hline & \multirow{2}{*}{ Accountability interinstitucional } & Capacidade de fiscalização do Legislativo \\
\hline & & Eficácia de restrições sobre o Executivo \\
\hline & Participação política & Comparecimento eleitoral \\
\hline & \multirow[b]{2}{*}{ Competição política } & Número de partidos \\
\hline & & $\begin{array}{l}\text { Diferença no número de vagas parlamentares entre os } \\
\text { dois partidos mais votados }\end{array}$ \\
\hline \multirow{2}{*}{ Conteúdo } & Liberdade & Índice de liberdades civis da Freedom House \\
\hline & Igualdade & Coeficiente de Gini \\
\hline Resultado & Responsividade & Satisfação popular com a democracia \\
\hline
\end{tabular}

Fonte: Elaboração própria a partir de Morlino, Dressel e Pelizzo (2011, p. 494)

\section{Apresentação dos dados}

A partir de agora, se avaliará, inicialmente, se a Venezuela continuava tendo uma democracia, com base nas sete condições de Dahl (2005), complementadas por duas sugeridas por O’Donnell (2004), a conclusão do mandato pelos governantes e a inexistência de restrições aos poderes legais das autoridades eleitas por parte de atores não eleitos ${ }^{2}$. Depois, caso estejam presentes os elementos que compõem a definição minimalista de democracia adotada neste trabalho, se analisará a qualidade do regime, com base nas três dimensões de Morlino, Dressel e Pelizzo (2011), complementadas por dois aspectos enfatizados por O’Donnell (2000), a aplicação igualitária das leis e a igualdade de tratamento pelos órgãos públicos ${ }^{3}$.

Na primeira condição de Dahl, a liberdade de formar e participar de organizações, as variáveis são liberdade de oposição de grupo e articulação de interesses por grupos associativos. Para ambas, há quatro categorias possíveis. No caso da primeira variável, a categoria que mais se ajusta é a de liberdade completa, em que grupos autônomos são livres para entrar na política e capazes de exercer oposição ao governo.

Uma acusação feita pela oposição é que o regime chavista promove prisões políticas. Ainda que haja casos que possam levar a essa interpretação, os mais célebres são os de Leopoldo López e Antonio

2 A justificativa é que as sete condições de Dahl não são suficientes se um governante tem seu mandato interrompido de uma forma que não está prevista na legislação e/ou sofre restrições para exercer suas funções por parte de atores não eleitos, como as Forças Armadas.

3 A subdimensão de Estado de Direito não se completa sem que a lei seja aplicada para todos, independentemente do nível de renda e da região do país onde se viva, e que todos tenham acesso e recebam atenção para suas demandas por parte dos órgãos públicos. 
Ledezma, não se trata de um recurso usado de forma recorrente para cercear a atividade dos grupos oposicionistas. Também se poderia fazer uma interpretação diferente das prisões que a oposição classifica como políticas, já que os envolvidos são acusados ou foram condenados por relação com ações violentas, no golpe contra Chávez em 2002 ou nos protestos contra Maduro em 2014, ou com planos para depor o atual presidente. A característica que prevalece, então, é que os diferentes grupos têm liberdade para se organizar politicamente e exercer oposição ao governo, como mostra o intenso embate político que tem marcado a Venezuela desde o início do regime chavista, seja pela via eleitoral, no debate público ou em manifestações de rua.

Para a variável de articulação de interesses por grupos associativos, a categoria que se aplica é a de significativa, já que as associações, de qualquer natureza, se organizam livremente para defender seus interesses e, em alguns casos, conseguem acumular força para exercer forte pressão. Um exemplo é a atuação da CTV (Confederação dos Trabalhadores da Venezuela) e da Fedecámaras (Federação de Câmaras e Associações de Comércio e Produção da Venezuela) nos primeiros anos de regime chavista. As duas entidades lideraram a manifestação antes do golpe contra Chávez em 2002 e a greve geral entre o fim daquele ano e o início de 2003 para exigir a saída do então presidente. Os resultados dessas iniciativas enfraqueceram a capacidade de pressão da CTV e da Fedecámaras, mas isso se deve, em grande parte, às suas próprias ações, e não à impossibilidade de se articular ${ }^{4}$.

Um fator que também contribuiu para enfraquecer as duas entidades e pode ser criticado é a política do regime chavista de patrocinar a formação de associações corporativas que the sejam leais e criem concorrência às que lhe fazem oposição. Essa prática pode ser configurada como interferência na liberdade de associação sindical, mas não implica que os grupos associativos não possam articular seus interesses.

A condição seguinte é a liberdade de expressão, que tem como única variável a liberdade de imprensa, dividida em quatro categorias. A que mais se ajusta à situação da Venezuela é a de liberdade intermitente, em que há censura ocasional ou seletiva tanto da imprensa doméstica quanto de correspondentes estrangeiros, ainda que essa censura não se estenda, no caso venezuelano, aos correspondentes que atuam no país. A decisão de não renovar a concessão da rede de televisão RCTV configurou um cerceamento da liberdade de imprensa e não pode ser justificada pelo argumento de que esse veículo apoiou o golpe de 2002. Até essa decisão, tomada em 2007, se podia dizer que havia plena liberdade de imprensa naVenezuela, o que permitiu que Chávez fos- se tratado de forma preconceituosa e que canais de televisão estimulassem e até articulassem o golpe contra ele.

Além da atuação na questão regulatória, a reação chavista ao papel da mídia no golpe de 2002 foi a criação de um aparato estatal de comunicação, com uma série de veículos. Se essa medida tinha a intenção de diversificar as opiniões na mídia, gerou um problema, a utilização dos veículos estatais e dos recursos públicos que eles consomem em benefício de uma corrente, criando desvantagens à oposição nas campanhas eleitorais, e ainda reforçou outro, o das ameaças e agressões a jornalistas. Com a construção do aparato estatal de comunicação, não são mais só os profissionais dos veículos privados que estão sujeitos à violência de partidários do grupo político adversário.

O direito de voto, comumente associado a um regime democrático, é a terceira condição para a existência de uma democracia, e tem como única variável o sistema eleitoral vigente, dividido em quatro categorias. A Venezuela se encaixa na categoria de sistema competitivo, em que há nenhuma proibição partidária ou proibição só de partidos extremistas ou extraconstitucionais.

Até 2010, quando a oposição pôde recuperar espaço na Assembleia Nacional por meio de eleições, o caso venezuelano se enquadrava na categoria de sistema parcialmente competitivo, em que um partido tem $85 \%$ ou mais das vagas parlamentares. Como as forças oposicionistas desistiram de disputar as eleições legislativas de 2005, por questionar a imparcialidade do CNE, o então partido de Chávez, o MVR (Movimento V República), ficou com 114 das 167 cadeiras na Assembleia Nacional, o que correspondia a $68,3 \%$ do total. Com a posterior criação do PSUV (Partido Socialista Unido da Venezuela) para reunir a base de sustentação ao chavismo, a ocupação por uma única força chegou a 89,2\% das vagas parlamentares. Nas eleições de 2010, a oposição reconquistou uma bancada significativa, permitindo que a Venezuela voltasse a se encaixar na categoria de sistema competitivo.

A quarta condição, o direito de que líderes políticos disputem apoio, se avalia por quatro variáveis: articulação de interesses por partidos políticos; sistema partidário: quantitativo; liberdade de oposição de grupo; e sistema eleitoral vigente. As duas últimas também são elementos de condições anteriores e já foram abordadas. Restam articulação de interesses por partidos políticos e sistema partidário: quantitativo, que se dividem, respectivamente, em quatro e seis categorias.

No caso da primeira variável, a categoria que mais se ajusta à situação da Venezuela é a de significativa. Assim como os grupos associativos, os partidos têm liberdade para se articular e defender seus interesses. Quando uma força desiste de disputar eleições, como

4 No curto prazo, a CTV e a Fedecámaras tiveram dificuldades para se reorganizar por causa dos processos judiciais contra alguns dos seus líderes, pelo envolvimento com o golpe de 2002 e a posterior greve geral. 
os partidos de oposição fizeram em 2005, a articulação dos seus interesses fica prejudicada, mas não se trata de uma limitação imposta, e sim de uma opção.

Para a variável de sistema partidário: quantitativo, a tarefa de classificar o caso venezuelano se dificulta, porque ele não apresenta traços de uma única categoria. Com base mais nos títulos do que nas descrições de cada uma, a classificação é de um sistema pluripartidário, em que há governo de coalizão ou de partido minoritário obrigatório se o sistema é parlamentar.

O primeiro problema dessa classificação é que a Venezuela não tem no momento um governo de coalizão nem minoritário, já que o PSUV conta com a maioria parlamentar e não governa em coalizão com outros partidos. Ao mesmo tempo, as descrições para as demais cinco categorias, de bipartidário ou efetivamente bipartidário, um partido e meio, um partido dominante, partido único e não sistema, também não servem para o caso venezuelano.

A melhor definição para o sistema partidário do país é de um pluralismo polarizado, porque há diversos partidos que, por causa do nível de polarização, estão divididos em dois grupos bem definidos, os chavistas e a oposição. Por outro lado, dos partidos que apoiaram a candidatura de Maduro, só o PSUV está representado no seu gabinete ministerial, fazendo com que não se caracterize a formação de uma coalizão para governar. A categoria de um partido e meio poderia ser uma solução, já que se define pela existência de uma oposição significativa, mas incapaz de conquistar a maioria. Desde que Chávez iniciou seu primeiro mandato, em 1999, os partidos que têm constituído a oposição ao chavismo não conseguem obter a maioria parlamentar, ainda que de forma conjunta, ou vencer as eleições presidenciais, mas, em termos do número de forças relevantes, não se pode classificar o sistema venezuelano como de um partido e meio, inclusive depois da criação do PSUV. Então, a categoria que mais se aproxima da realidade é a de pluripartidário.

A próxima condição são fontes alternativas de informação, cujas três variáveis, liberdade de oposição de grupo, liberdade de imprensa e sistema partidário: quantitativo, já foram abordadas na avaliação de condições anteriores. As categorias estabelecidas para cada uma foram, respectivamente, de liberdade significativa, liberdade intermitente e sistema pluripartidário. Os problemas mais sérios, portanto, se concentram na segunda variável.

Assim como no caso do direito de voto, a sexta condição, as eleições livres e limpas, é comumente associada a um regime democrático. Todas as suas quatro variáveis, liberdade de oposição de grupo, liberdade de imprensa, sistema eleitoral vigente e sistema partidário: quantitativo, também já foram abordadas na avaliação de condições anteriores. Porém, por causa da ênfase que o conceito de eleições livres e limpas coloca na lisura do processo, é importante retomar a análise da variável de sistema eleitoral vigente, a que mais se vincula aos atributos de uma eleição, e abordar esse tema.

As vitórias eleitorais do chavismo têm gerado acusações de fraude, com maior ou menor intensidade conforme o caso. Essas reações se devem ao grau de polarização no cenário político da Venezuela e à incapacidade do órgão regulador das eleições, o CNE, de conquistar a confiança da população, sobretudo da parcela que se situa no campo da oposição. A percepção desse grupo é a de que o CNE se compõe de aliados do chavismo e o favorece.

De fato, os aliados predominam no órgão eleitoral, porque os membros do CNE são designados pela Assembleia Nacional, em que o chavismo tem conquistado a maioria ou até a totalidade das vagas em certos momentos. Por outro lado, essa situação não implica em favorecimento na apuração dos votos, já que o sistema de votação na Venezuela é totalmente automatizado e tem demonstrado sua confiabilidade, que vinha sendo atestada por observadores internacionais até o CNE deixar de autorizar essa categoria de atuação ${ }^{5}$.

Os problemas se concentram na falta de confiança do conjunto da população e dos atores políticos no CNE e na utilização que o chavismo faz da máquina do Estado em campanhas eleitorais, com ações que vão do emprego de recursos públicos em mobilizações ao uso dos veículos estatais de comunicação em benefício próprio. No caso de disputas apertadas, como o das eleições presidenciais de 2013, esses problemas se potencializam e podem gerar reações extremadas. Foi o que ocorreu depois do anúncio da vitória de Maduro. Seu principal adversário não reconheceu os resultados e convocou manifestações de rua para pressionar por uma recontagem dos votos. De qualquer maneira, as questões apontadas não são suficientes para alterar a avaliação já feita de que, na variável sistema eleitoral vigente, a categoria que se aplica à Venezuela é a de sistema competitivo.

Por fim, a sétima condição é instituições para fazer com que as políticas governamentais dependam de votos e outras expressões de preferência, que têm quatro variáveis, condição constitucional do atual regime, agregação de interesses pelo Legislativo, distribuição horizontal do poder e condição atual do Legislativo. No caso da primeira variável, dividida em três categorias, a que mais se ajusta à Venezuela é a de regime constitucional, em que o governo é conduzido com referência a normas constitucionais reconhecidas.

Ainda que não falte quem defenda que o regime chavista é autoritário (Corrales, 2006; Corrales e Penfold, 2007; Kornblith, 2007) ou até totalitário, que são 
as demais categorias para a variável de condição constitucional do atual regime, ele não se enquadra nas descrições de nenhuma dessas categorias. Segundo a descrição para a categoria de regime autoritário, não existe limitação constitucional efetiva ou se recorre com absoluta regularidade a poderes extraconstitucionais, características que, ao menos nesses graus descritos, não estão presentes na Venezuela.

Para a variável de agregação de interesses pelo Legislativo, dividida em quatro categorias, a que se aplica à Venezuela é a de significativa. Essa é a situação desde que os parlamentares que compõem a legislatura 2011-2015 da Assembleia Nacional tomaram posse, possibilitando que a oposição voltasse a ter uma bancada significativa na Casa. Até então, uma parcela importante da sociedade venezuelana não estava representada no Legislativo, por causa da desistência da oposição de disputar as eleições parlamentares de 2005, o que deixou a Assembleia Nacional com uma capacidade limitada de aglutinação de interesses durante a legislatura 2006-2010.

$\mathrm{Na}$ variável seguinte, de distribuição horizontal do poder, a Venezuela apresenta problemas sérios. Entre as três categorias dessa variável, a mais apropriada para o caso venezuelano é a de distribuição limitada, em que um braço do governo não conta com genuína autonomia funcional, ou dois braços do governo têm limitada autonomia funcional. Com a participação da oposição nas eleições parlamentares de 2010, o Legislativo pôde recuperar em parte a autonomia em relação ao Executivo, já que os partidos oposicionistas conquistaram 65 vagas, de um total de 165 deputados. Essa recuperação de autonomia não foi completa porque o chavismo continuou tendo a maioria na Assembleia Nacional e, em um cenário polarizado, pouco delibera sobre os projetos submetidos pelo Executivo.

O Judiciário, por outro lado, enfrenta dificuldades para tomar decisões autônomas diante das pressões do Executivo, diretamente ou por meio da convocação de manifestações de rua. A independência do Judiciário também ficou prejudicada com a ampliação de 20 para 32 no número de magistrados da principal corte da Venezuela, o TSJ (Tribunal Supremo de Justiça). Como a Constituição de 1999 estabelece que a Assembleia Nacional toma a decisão final sobre as nomeações dos integrantes do TSJ, os 12 novos magistrados foram designados pela maioria que o chavismo tinha na Casa na legislatura 2001-2005. Para agravar o quadro, os integrantes do tribunal cumprem um mandato de 12 anos e podem ser removidos dos seus cargos por uma maioria de dois terços dos deputados da Assembleia Nacional, quórum que o chavismo tinha na legislatura 2006-2010.

Considerando que a divisão de poderes na Venezuela ainda conta com mais dois ramos, o Cidadão e o Eleitoral, e que as designações dos seus integrantes também são feitas pela Assembleia Nacional, em que o chavismo tem obtido a maioria ou até a totalidade das vagas, a concentração de poderes no Executivo e a debilidade dos controles sobre ele se agravam.

Resta a quarta variável, de condição atual do Legislativo, que se divide em quatro categorias. Para o caso venezuelano, a que mais se ajusta é a de Legislativo parcialmente efetivo, em que ele tende a ser dominado pelo Executivo ou está parcialmente limitado no exercício efetivo das suas funções. Essa situação se deve à maioria do chavismo na Assembleia Nacional que, em um cenário polarizado, pouco delibera sobre os projetos do Executivo. Não se trata, portanto, de uma limitação imposta sobre o Parlamento, e sim de uma atuação legislativa condicionada por aspectos institucionais e políticos.

Há ainda as duas condições acrescentadas por O’Donnell (2004), a conclusão do mandato pelos governantes e a inexistência de restrições aos poderes legais das autoridades eleitas por parte de atores não eleitos. A Venezuela teve problemas para cumprir o primeiro desses requisitos entre 2002 e 2004, quando houve um golpe de Estado que tirou Chávez do poder por 48 horas e ações para forçá-lo a renunciar ou até tentar um novo golpe. $\mathrm{O}$ que possibilitou que a situação se estabilizasse foi um mecanismo institucional, a realização em 2004 de um referendo sobre a continuidade ou não do mandato de Chávez. Com a vitória chavista e algumas medidas que já estavam em andamento, como a cooptação das Forças Armadas, ele pôde concluir os seis anos como presidente conquistados em 2000. A disputa sobre os resultados das eleições presidenciais de 2013 recolocou no horizonte a possibilidade de uma nova tentativa de golpe, mas isso se enfraqueceu depois da decisão do CNE de completar a auditoria de todas as urnas eletrônicas.

A solução da questão da conclusão do mandato pelos governantes possibilitou que, desde 2004, também se cumprisse na Venezuela a condição da inexistência de restrições aos poderes legais das autoridades eleitas por parte de atores não eleitos. $\mathrm{Na}$ verdade, como se pôde ver no caso da sétima condição de Dahl, Chávez se ocupou de concentrar poder, debilitando os controles sobre o Executivo.

Das sete condições de Dahl (2005), a Venezuela obtém a pontuação que significa a melhor situação possível em três: liberdade de formar e participar de organizações, direito de voto e direito de que líderes políticos disputem apoio (ver quadro abaixo). Em três, liberdade de expressão, fontes alternativas de informação e eleições livres e limpas, o regime venezuelano ganha um ponto em cada uma delas e piora de situação. Os problemas mais sérios estão na condição de instituições para fazer com que as políticas governamentais dependam de eleições e outras expressões de preferência, em que a Venezuela fica com dois pontos acima do melhor valor possível. 
Condições e variáveis, com as categorias e os pontos para a Venezuela

\begin{tabular}{|c|c|c|c|}
\hline Condição & Variáveis & Categorias & Pontos \\
\hline \multirow{2}{*}{$\begin{array}{l}\text { Liberdade de formar e participar de } \\
\text { organizações }\end{array}$} & Liberdade de oposição de grupo & Completa & 1 \\
\hline & Articulação de interesses por grupos associativos & Significativa & 1 \\
\hline Liberdade de expressão & Liberdade de imprensa & Intermitente & 2 \\
\hline Direito de voto & Sistema eleitoral vigente & Competitivo & 1 \\
\hline \multirow{4}{*}{$\begin{array}{l}\text { Direito de que líderes políticos } \\
\text { disputem apoio }\end{array}$} & Articulação de interesses por partidos políticos & Significativa & 1 \\
\hline & Sistema partidário: quantitativo & Pluripartidário & 1 \\
\hline & Liberdade de oposição de grupo & Completa & 1 \\
\hline & Sistema eleitoral vigente & Competitivo & 1 \\
\hline \multirow{3}{*}{ Fontes alternativas de informação } & Liberdade de oposição de grupo & Completa & 1 \\
\hline & Liberdade de imprensa & Intermitente & 2 \\
\hline & Sistema partidário: quantitativo & Pluripartidário & 1 \\
\hline \multirow{4}{*}{ Eleições livres e limpas } & Liberdade de oposição de grupo & Completa & 1 \\
\hline & Liberdade de imprensa & Intermitente & 2 \\
\hline & Sistema eleitoral vigente & Competitivo & 1 \\
\hline & Sistema partidário: quantitativo & Pluripartidário & 1 \\
\hline \multirow{4}{*}{$\begin{array}{l}\text { Instituições para que as políticas } \\
\text { governamentais dependam de } \\
\text { votos e outras expressões de } \\
\text { preferência }\end{array}$} & Condição constitucional do atual regime & Constitucional & 1 \\
\hline & Agregação de interesses pelo Legislativo & Significativa & 1 \\
\hline & Distribuição horizontal do poder & Limitada & 2 \\
\hline & Condição atual do Legislativo & $\begin{array}{l}\text { Parcialmente } \\
\text { efetivo }\end{array}$ & 2 \\
\hline $\begin{array}{l}\text { Conclusão do mandato pelos } \\
\text { governantes }\end{array}$ & - & $\begin{array}{l}\text { Mandatos } \\
\text { concluídos }\end{array}$ & - \\
\hline $\begin{array}{l}\text { Inexistência de restrições aos } \\
\text { poderes legais das autoridades } \\
\text { eleitas por atores não eleitos }\end{array}$ & - & $\begin{array}{l}\text { Restrições } \\
\text { inexistentes }\end{array}$ & - \\
\hline
\end{tabular}

Fonte: Elaboração própria a partir de Dahl (2005) e O’Donnell (2004)

No total, a Venezuela obtém 24 pontos, em uma escala que vai de 19 , a melhor situação, a 80 , a pior. Dahl não esclarece nos apêndices do seu livro quais são as faixas de pontuação que correspondem a cada tipo de regime. Estabelecendo os tipos ideais de democrático, semidemocrático, autoritário e totalitário, o que torna a faixa de pontuação para a democracia mais estreita e exigente, e dividindo a diferença entre 19 e 80 por quatro, a cada 15,25 pontos se configuraria um tipo. Com isso, a faixa de regime democrático iria de 19 a 34,25 , a de semidemocrático, até 49,5 , a de autoritário, até 64,75 , e a de totalitário, até 80 , deixando o regime chavista na categoria de democrático.

Ainda que não se adote essa divisão de faixas, a distância de cinco pontos para o melhor valor possível não é suficiente para fazer com que a Venezuela deixe de ter uma democracia. Os problemas mais sérios do regime venezuelano se referem à liberdade de imprensa, que se tornou intermitente desde a não renovação da concessão do canal oposicionista RCTV, à concentração de poderes no Executivo e ao enfraquecimento dos controles sobre ele e da autonomia dos demais ramos de poder.

Com as pontuações para cada variável e a agregação dos resultados, os problemas nas diferentes condições que caracterizam uma democracia podem ser identificados e considerados em conjunto na avaliação do tipo de regime existente. Ao mesmo tempo, em razão da importância que a realização de eleições livres e limpas tem para a definição de democracia adotada 
aqui, uma situação crítica nessa condição significaria que o regime não é democrático, independentemente da pontuação total obtida.

Como a Venezuela continuava tendo uma democracia, se pode passar à análise da sua qualidade. $\mathrm{Na}$ dimensão de procedimento, Estado de Direito, accountability eleitoral, accountability interinstitucional, participação política e competição política são os aspectos avaliados. A subdimensão de Estado de Direito tem três indicadores, respeito do governo à integridade dos cidadãos, eficácia do governo e grau de corrupção. Quanto ao primeiro indicador, o PROVEA (Programa Venezuelano de Educação-Ação em Direitos Humanos) divulga regularmente dados sobre violações à integridade pessoal, que a entidade divide em cinco tipos de casos, tortura, tratamento ou pena cruel, inumana ou degradante, feridos, busca ilegal e ameaça ${ }^{6}$.

Para o período de janeiro de 2013 a dezembro de 2013, o PROVEA recebeu as denúncias de 306 casos de violações à integridade pessoal, com um saldo de 419 vítimas que puderam ser contadas individualmente. Os números cresceram em comparação ao mesmo período de 2012, para o qual foram recebidas as denúncias de 103 casos, com 333 vítimas. Também houve aumento no número de casos em comparação aos períodos de outubro de 1997 a setembro de 1998, o último relativo ao governo de Rafael Caldera, e de outubro de 1999 a setembro de 2000, o primeiro que se refere só à gestão Chávez. Foram 229 casos para a parte final da administração Caldera, com 442 vítimas, e 254 casos para a parte inicial do governo Chávez, com 527 vítimas. Na comparação com o período relativo à gestão Caldera, é necessário levar em conta que, a partir do relatório de 2000, o PROVEA adotou dois novos tipos de violações à integridade pessoal, os de busca ilegal e ameaça.

Para a eficácia do governo, o Banco Mundial tem, entre seus indicadores de governança, um que recebe o mesmo nome de eficácia do governo e mede a percepção sobre a qualidade do serviço público, seu grau de independência de pressões políticas, a qualidade da formulação e da implementação de políticas e a credibilidade do comprometimento do governo com suas políticas ${ }^{7}$. Em 2013, a Venezuela superou 13,40\% dos demais países do mundo no ranking desse indicador. Foi um desempenho melhor em relação a 2012 e pior em relação a 2000, o primeiro ano de Chávez com dados disponíveis, e 1998, o último ano de Caldera. Nesses três anos, a pontuação venezuelana superou, respectivamente, $12,92 \%, 24,39 \%$ e 19,02\% dos demais países.

A subdimensão de Estado de Direito ainda é avaliada pelo grau de corrupção. O próprio chavismo, já com seu líder original e agora com Maduro, considera essa questão grave e tem insistido na necessidade de enfrentá-la. Na edição de 2014 do índice de percepção da corrupção da Transparência Internacional, a Venezuela obteve 19 pontos, em um escala que vai de 0 , o pior desempenho, a 100 , o melhor, e ficou na $161^{\circ}$ colocação entre 175 países ou territórios ${ }^{8}$. Houve a queda de uma posição em relação a 2013, quando a Venezuela ocupou o $160^{\circ}$ lugar entre 177 países ou territórios, com 20 pontos. Na comparação de 2014 com 1999 e 1998, respectivamente, o primeiro ano de Chávez e o último de Caldera, a situação também piorou. Para 1999, a Venezuela obteve 2,6 pontos, em uma escala de 0 a 10 , e a $75^{\text {a }}$ colocação entre 99 países ou territórios. Para 1998, foram 2,3 pontos, o que significou a $77^{a}$ posição entre 85 países ou territórios.

Os três indicadores para a subdimensão de Estado de Direito podem ser complementados por dois aspectos que O’Donnell (2000) enfatiza, a aplicação igualitária das leis e a igualdade de tratamento pelos órgãos públicos. Uma marca do chavismo são os programas sociais, que, entre outras funções, levam serviços básicos à população carente. Essa política de extensão de direitos às classes menos favorecidas é uma tentativa de tornar a validade das leis mais igualitária e a prestação de serviços públicos mais equilibrada. Também se pode argumentar que grupos privilegiados durante os anos de predominância do bipartidarismo perderam vantagens com a ascensão de Chávez ao poder, ainda que alguns tenham recuperado força, por se convencer de que seria mais vantajoso se aliar ao chavismo ou pelo temor de sofrer represálias nos seus negócios com o Estado.

Ao mesmo tempo, o regime chavista concentrou poder no Executivo, o que prejudica a eficácia dos órgãos judiciários e de controle em fazer a lei valer igualmente para todos. Nas avaliações de governança do Banco Mundial, a Venezuela superou só 0,95\% dos demais países do mundo no ranking para 2013 do indicador de governo da lei, que mede a percepção sobre a confiança e o respeito às regras ${ }^{9}$. Esse desempenho repetiu o de 2012 e foi muito pior do que o de 2000 , o primeiro ano de Chávez com dados disponíveis, e o de 1998, o último ano de Caldera. Tanto em 2000 quanto

6 Informes anuais do PROVEA, consultados em 21 mai. 2015, disponíveis em <http://www.derechos.org.ve/>.

7 Indicadores de governança do Banco Mundial, consultados em 21 mai. 2015, disponíveis em <http://info.worldbank.org/governance/wgi/index. aspx\#home>.

8 Índice de percepção da corrupção da Transparência Internacional, consultado em 21 mai. 2015, disponível em <http://www.transparency.org/>. 9 Indicadores de governança do Banco Mundial, consultados em 21 mai. 2015, disponíveis em <http://info.worldbank.org/governance/wgi/index. aspx\#home>. 
em 1998, a Venezuela superou 22,97\% dos demais países. Se a lei, no geral, vale pouco, os pobres tendem a ser os mais afetados por essa situação.

Passando à subdimensão de accountability eleitoral, os indicadores são a liberdade de imprensa e a autodeterminação eleitoral. O primeiro deles já foi abordado na avaliação sobre o cumprimento das condições para a existência de uma democracia na Venezuela, com a conclusão de que a liberdade de imprensa se tornou intermitente no país desde a não renovação da concessão do canal oposicionista RCTV.

Também tem havido problemas para a autodeterminação eleitoral dos votantes na Venezuela. Segundo a oposição, funcionários públicos sofrem coerção para votar a favor do chavismo. Nas eleições presidenciais de 2013, novas denúncias nesse sentido foram feitas. O caso mais célebre foi o da lista Tascón. Em 2004, Luis Tascón, então deputado na Assembleia Nacional pelo MVR, publicou na sua página na internet uma lista, que não havia se tornado pública até então, com os mais de 2,4 milhões de eleitores que haviam assinado a petição pela convocação de um referendo sobre a continuidade ou não do mandato de Chávez. Essa atitude desencadeou uma série de denúncias de que a lista estaria sendo utilizada para a adoção de represálias contra funcionários públicos que haviam assinado a petição.

A subdimensão de accountability interinstitucional, que se avalia por dois indicadores, capacidade de fiscalização do Legislativo e eficácia de restrições sobre o Executivo, é até mais problemática na Venezuela, como mostrou a análise do sétimo requisito para a existência de uma democracia, que trata, entre outras questões, da distribuição horizontal do poder e da condição do Legislativo. No caso do primeiro indicador, a Assembleia Nacional conta com capacidade de fiscalização sobre o Executivo. Um instrumento para isso é a possibilidade de destituir o vice-presidente e os ministros por uma maioria de três quintos dos deputados. Ademais, os poderes constitucionais do presidente venezuelano não são fortes, já que ele não conta com a possibilidade de vetar leis aprovadas pelo Legislativo nem com a iniciativa exclusiva de leis em certas áreas, o que aumenta a margem de ação da Assembleia Nacional.

Essa capacidade de fiscalização do Legislativo, porém, não tem sido exercida. Isso se deve à maioria que o chavismo tem mantido na Assembleia Nacional e que, em um cenário polarizado, pouco delibera sobre as ações e os projetos do Executivo, o que entra no âmbito do indicador seguinte, a eficácia das restrições sobre o Executivo. Os demais Poderes que poderiam exercer essa função de controle também não o fazem devidamente, porque, entre outros motivos, seus integrantes são designados pela Assembleia Nacional. O TSJ, que é responsável pelo controle constitucional das leis, também está sob essas regras de nomeação e até pode ter seus integrantes removidos dos cargos por uma maioria de dois terços dos deputados da Assembleia Nacional, quórum que o chavismo tinha na legislatura 2006-2010.

Para a subdimensão de participação política, há um único indicador, o comparecimento eleitoral. Na Venezuela, o voto não é obrigatório. Apesar disso, a abstenção nas eleições presidenciais tem caído desde 2000, quando Chávez se reelegeu pela primeira vez ${ }^{10}$. Entre a disputa anterior à primeira vitória chavista e 2000, a abstenção esteve em um nível alto e foi de 39,84\% em 1993, 36,54\% em 1998 e 43,69\% em 2000. Na edição seguinte, em 2006, já houve uma queda acentuada, para $25,30 \%$. Essa trajetória continuou nas duas últimas eleições presidenciais, em 2012 e 2013, que tiveram abstenções de, respectivamente, $19,51 \%$ e $20,22 \%$.

$\mathrm{Na}$ subdimensão de competição política, são dois indicadores, número de partidos e diferença no número de vagas parlamentares entre as duas forças mais votadas. Nas últimas eleições para a Assembleia Nacional, em 2010, 11 partidos obtiveram vagas, sem contar as legendas simbólicas pelas quais se elegeram os deputados da representação indígena. Hoje, são 12 as forças políticas representadas no Legislativo unicameral venezuelano. Trata-se, portanto, de um sistema multipartidário com alta fragmentação. A polarização também é uma característica marcante, já que há dois grupos bem definidos, o chavismo e a oposição.

Por outro lado, a diferença no número de vagas parlamentares entre os dois partidos mais votados foi grande nas últimas eleições para a Assembleia Nacional. O PSUV obteve 96 cadeiras, contra 22 da AD (Ação Democrática). É uma diferença de 74 deputados, o que corresponde a 44,85\% das 165 vagas no Legislativo. Portanto, se a fragmentação partidária alta é um indicador de competição acirrada, o resultado da distribuição das cadeiras entre as forças políticas vai em direção contrária. Isso não significa, porém, que os partidos oposicionistas sejam fracos naVenezuela, pelo contrário, como mostraram as duas últimas eleições presidenciais.

Para a avaliação da dimensão de conteúdo, a liberdade e a igualdade são os aspectos abordados. $\mathrm{O}$ indicador para a subdimensão de liberdade é o índice de liberdades civis da Freedom House. O conceito da Venezuela para 2014 foi 5, em uma escala que vai de 0 , o melhor desempenho, a 7 , o pior ${ }^{11}$. A nota do país tem sido a mesma desde o relatório que se refere a 2010. Na maior parte dos 14 anos de Chávez no poder, o conceito venezuelano foi 4, recebido para 1999 e todos os anos entre 2002 e 2009. Sob o regime chavista, houve

10 Banco de dados eleitorais do CNE, consultado em 28 abr. 2013, disponível em <http://www.cne.gov.ve/web/>

11 Relatórios anuais de liberdades no mundo da Freedom House, consultados em 21 mai. 2015, disponíveis em <http://www.freedomhouse.org/ report-types/freedom-worlds. 
uma piora em relação ao último ano do governo anterior, o de 1998, quando a Venezuela teve a nota $3 \mathrm{em}$ liberdades civis e a classificação geral de livre. Desde o primeiro ano de Chávez no poder, o país tem ficado com a classificação de parcialmente livre. As categorias possíveis são as de livre, parcialmente livre e não livre. Com base nos seus índices de direitos políticos e de liberdades civis, a Freedom House estabelece anualmente a classificação mais adequada para cada caso avaliado.

Apesar de amplamente utilizados nos trabalhos empíricos sobre regimes democráticos, os índices da Freedom House têm uma série de problemas. Bollen e Paxton (2000) mostram que há um viés político contra governos de esquerda. Levine e Molina (2007) identificam a origem desse viés na inclusão de liberdade econômica e direito à propriedade privada como um critério para a avaliação dos níveis de liberdade e democracia. Por fim, Mainwaring, Brinks e Pérez-Liñán (2001) apontam mais problemas, como a falta de critérios e regras claras para a definição dos conceitos e distorções nos índices por causa de avaliações indevidamente negativas ou de variações nas notas que se devem mais a mudanças nos critérios do que a alterações nas condições reais. Assim, eles recomendam cuidado no uso dos índices da Freedom House.

Como alternativa ao índice de liberdades civis da Freedom House, há, por exemplo, o índice de igualdade perante a lei e liberdades individuais do projeto V-DEM (Varieties of Democracy). A Venezuela obteve o valor de 0,58 para 2012, o último ano com avaliação disponível para o país, em uma escala que vai de 0 , o pior resultado, a 1, o melhor ${ }^{12}$. O valor para 1998, o último ano antes de Chávez, foi de 0,81. Desde então, a trajetória venezuelana nesse indicador é descendente. $\mathrm{Na}$ escala relativa, levando em conta a situação dos demais países avaliados, a Venezuela fica em uma posição intermediária, um pouco acima da metade do intervalo entre os níveis mínimo e máximo.

O coeficiente de Gini é o indicador com que se avalia a subdimensão de igualdade. Para medir a distribuição de renda, ele varia de 0 , uma situação de perfeita igualdade, a 1, uma situação de perfeita desigualdade. Na Venezuela, o coeficiente de Gini passou de 0,498 em 1999, o primeiro ano de Chávez, para 0,407 em 2013, segundo a CEPAL (Comissão Econômica para a América Latina e o Caribe $)^{13}$. Em 1997, o último ano de Caldera para o qual há dados disponíveis, o índice era de 0,507 .

Por fim, há a dimensão de resultado, em que a responsividade é o único aspecto avaliado. Essa subdimensão tem como indicador o grau de satisfação popular com a democracia. Na edição de 2013 da pesquisa Latinobarômetro, a Venezuela ficou acima do nível regional, com $42 \%$ de satisfação contra os 39\% de média para os 18 países da América Latina e do Caribe pesquisados ${ }^{14}$. Foi o sétimo maior índice. Por outro lado, houve uma queda em relação a 2011, o ano da edição anterior da pesquisa, quando a satisfação com a democracia foi de 45\% na Venezuela. Esse percentual é o mesmo de 1998, o ano da primeira vitória eleitoral de Chávez e o último do seu antecessor. A Venezuela, porém, vinha de índices mais baixos em 1996 e 1997, quando teve, respectivamente, $30 \%$ e $35 \%$ de satisfação com sua democracia.

\section{Conclusões}

Se a avaliação é de que aVenezuela continuava tendo uma democracia, há uma série de problemas na sua qualidade, que se concentram na dimensão de procedimento. O país tem piorado no respeito do governo à integridade dos cidadãos, medido pelo número de casos denunciados ao PROVEA, nos indicadores do Banco Mundial para eficácia do governo e Estado de Direito e no índice de percepção da corrupção da Transparência Internacional, todos referentes à subdimensão de Estado de Direito, que é o primeiro dos aspectos procedimentais da qualidade democrática.

Há problemas em mais duas subdimensões procedimentais, ambas de accountability, a eleitoral e a interinstitucional. Em relação à primeira delas, a liberdade de imprensa se tornou intermitente desde que a concessão do canal oposicionista RCTV não foi renovada, e se acumulam denúncias de que funcionários públicos sofrem coerção para votar a favor do chavismo, tendo a lista Tascón como o caso mais célebre. Na subdimensão de accountability interinstitucional, as questões são até mais graves. A capacidade de fiscalização do Legislativo não tem sido exercida, devido à maioria que o chavismo preserva na Assembleia Nacional e que, em um cenário polarizado, pouco delibera sobre as ações e os projetos do Executivo. Os demais Poderes que poderiam exercer a função de controle sobre o Executivo também não o fazem devidamente, porque, entre outros motivos, seus integrantes são designados pela maioria chavista na Assembleia Nacional.

A Venezuela ainda tem problemas na dimensão de conteúdo, por causa do seu desempenho no índice de liberdades civis da Freedom House, que é o indicador para a subdimensão de liberdade. Desde o relatório que se refere a 2010, o país tem recebido o conceito 5 , em uma escala que vai de 0 , o melhor resultado, a 7 , o pior. 
Esse desempenho ruim precisa ser relativizado por causa do viés político da Freedom House contra governos de esquerda. Utilizando um indicador alternativo, o índice do projeto V-DEM para igualdade perante a lei e liberdades individuais, a situação da Venezuela também é ruim, com uma trajetória descendente desde 1998, o último ano antes de Chávez, e um valor de $0,58 \mathrm{em}$ uma escala que vai de 0 , o pior resultado, a 1 , o melhor.

Em relação aos demais aspectos da qualidade de uma democracia, a Venezuela se sai melhor. Na dimensão de procedimento, a abstenção nas eleições presidenciais tem caído desde 2000, o que serve como indicador para a subdimensão de participação política, e há um número alto de partidos representados na Assembleia Nacional, 12 no primeiro semestre de 2015, um indicador para a subdimensão de competição política. Nos aspectos relativos ao conteúdo, o coeficiente de Gini, que é o indicador para a subdimensão de igualdade, está em trajetória descendente desde 1999. Por fim, na dimensão de resultado, o grau de satisfação com a democracia, que é o indicador para a subdimensão de responsividade, foi superior à média regional em 2013.

A situação na dimensão de conteúdo é ilustrativa do panorama para a qualidade da democracia venezuelana. Nos aspectos dessa dimensão, a Venezuela se sai mal na liberdade e bem na igualdade. Isso é um sintoma da prioridade adotada no regime chavista. Os esforços têm se concentrado na redução da pobreza e da desigualdade, ainda que, ao mesmo tempo, liberdades fundamentais, como a de imprensa, a autonomia dos Poderes e os controles sobre o Executivo se debilitem.

É surpreendente, ademais, que até em uma variante da democracia que tem sido enfatizada pelo regime chavista, a participativa, o desempenho da Venezuela está aquém do esperado. O projeto V-DEM tem um índice de democracia participativa, em que a Venezuela obteve um valor de 0,32 para 2012, o último ano com dado disponível para o país, em uma escala que vai de 0 , o pior resultado, a 1, o melhor. Com o chavismo no poder, a trajetória da Venezuela nesse indicador é descendente desde 1998, o último ano antes de Chávez. O único aspecto que relativiza esse desempenho é que o índice de democracia participativa do projeto V-DEM também leva em conta o nível de democracia eleitoral.

As dúvidas que todas essas constatações geram são se, com o fim do período de Chávez no poder e o início do governo Maduro, persistirá a brecha entre liberdade e Estado de Direito, por um lado, e igualdade, por outro, em benefício da última, e até que ponto a corda poderá ser esticada sem que se rompa e leve consigo a democracia na Venezuela.

\section{Referências}

BOLLEN, Kenneth A.; PAXTON, Pamela. Subjective measures of liberal democracy. Comparative Political Studies, v. 33, n. 2, p. 58-86, 2000.

CORRALES, Javier. Hugo Boss. How Chávez is refashioning dictatorship for a democratic age. Foreign Policy, n. 152, p. 32-40, 2006.

_ \& PENFOLD, Michael. Venezuela: crowding out the opposition. Journal of Democracy, v. 18, n. 2, p. 99-113, 2007.

DAHL, Robert A. Poliarquia: participação e oposição. São Paulo: EdUSP, 2005.

GUNTHER, Richard; DIAMANDOUROS, P. Nikiforos; PUHLE, Hans-Jürgen (orgs.). The politics of democratic consolidation. Baltimore:The Johns Hopkins University Press, 1995. KORNBLITH, Miriam. Venezuela: calidad de las elecciones y calidad de la democracia. América Latina Hoy, n. 45, p. 109124, 2007.

LEVINE, Daniel H.; MOLINA, José Enrique. La calidad de la democracia en América Latina: una visión comparada. América Latina Hoy, n. 45, p.17-46, 2007.
LIJPHART, Arend. Modelos de democracia. Desempenho e padrões de governo em 36 países. Rio de Janeiro: Civilização Brasileira, 2003.

MAINWARING, Scott;BRINKS, Daniel; PÉREZ-LIÑÁN, Aníbal. Classificando regimes políticos na América Latina, 1945-1999. Dados, v. 44, n. 4, p. 645-687, 2001.

MORLINO, Leonardo; DRESSEL, Björn; PELIZZO, Riccardo. The quality of democracy in Asia-Pacific: issues and findings. International Political Science Review, v. 32, n. 5, p. 491-511, 2011.

O'DONNELL, Guillermo. Poliarquias e a (in) efetividade da lei na América Latina: uma conclusão parcial. In: MÉNDEZ, Juan E.; O'DONNELL, Guillermo; PINHEIRO, Paulo Sérgio (Orgs.). Democracia, violência e injustiça. O não-Estado de Direito na América Latina. São Paulo: Paz e Terra, 2000.

Otra institucionalización. In: O’DONNELL, Guillermo. Contrapuntos: ensayos escogidos sobre autoritarismo y democratización. Buenos Aires: Paidós, 2004. 


\title{
Venezuela on test: the quality of the Venezuelan democracy in electoral year
}

\begin{abstract}
:
The presidential elections of 2013, the most close since the rise of Hugo Chávez, offered an especial opportunity to analyze the quality of the democracy in Venezuela. The paper makes a point doing a previous evaluation of the continuity of democratic regime in the country in order to, depending on the result, proceed to the analysis of its quality, because it would be impossible to analyze the quality of something which doesn't exist. Using criteria, based on Dahl and O'Donnell, and variables, categories and scores for each criterion, it was possible to evaluate that, despite the problems regarding freedom of press, concentration of powers on the Executive and lack of autonomy of the other branches of power,Venezuela still had a democracy. This finding takes in account the score for the group of variables, avoiding that a problem leads by itself to the inexistence of democracy, unless this problem means that there aren't free and fair elections. In the analysis of the democratic quality, using a methodology developed by Morlino and collaborators, the conclusion is that there is a priority to equality over liberty in the dimension of content, in addition to a series of problems in the dimension of procedure.
\end{abstract}

Key words: Venezuela; quality of democracy; Hugo Chávez; electoral year; Nicolás Maduro.

\section{La Venezuela en teste: la cualidad de la democracia venezolana en año electoral}

\begin{abstract}
Resumen:
Las elecciones presidenciales de 2013, que fueron las más disputadas desde la ascensión de Hugo Chávez, ofrecieron una oportunidad especial para el análisis de la cualidad de la democracia en Venezuela. El artículo se diferencia al hacer una evaluación previa sobre la continuidad o no del régimen democrático en el país para, conforme el resultado, pasar al análisis de su cualidad, ya que no se puede analizar a cualidad de algo que no exista. A partir de la definición de criterios, con base en Dahl y O’Donnell, y de variables, categorías y puntuaciones para cada criterio, fue posible evaluar que, a pesar de los problemas relativos a libertad de prensa, concentración de poderes en el Ejecutivo y falta de autonomía de las demás ramas de poder,Venezuela continuaba tiendo una democracia. Ese resultado considera la puntuación para el conjunto de variables, evitando que un problema, aislado, implique la inexistencia de democracia, a menos que ese problema signifique que no haya elecciones competitivas y limpias. En el análisis de la cualidad democrática, a partir de metodología definida por Morlino y colaboradores, la conclusión fue que hay una prioridad a la igualdad en perjuicio de la libertad en la dimensión de contenido, además de una serie de problemas en la dimensión de procedimiento.
\end{abstract}

Palabras clave:Venezuela; cualidad de la democracia; Hugo Chávez; año electoral; Nicolás Maduro. 
